\title{
Validation of High-Performance Liquid Chromatography Method for Determination of Vitamin B1 in Powder Milk
}

\author{
Supriyono $^{\mathrm{a}, *}$, Mudhiah Fitrillah ${ }^{\mathrm{a}}$, Arie Pratama Putra ${ }^{\mathrm{a}}$ \\ ${ }^{\text {a }}$ Department of Chemical Analysis, Politeknik AKA Bogor, Bogor 16154, Indonesia \\ *Corresponding author: supriyono272@gmail.com
}

https://doi.org/10.14710/jksa.23.5.177-182

\section{Article Info \\ Article history: \\ Received: $8^{\text {th }}$ December 2019 Revised: $6^{\text {th }}$ April 2020 \\ Accepted: $20^{\text {th }}$ April 2020 \\ Online: $31^{\text {st }}$ May 2020}

Keywords:

HPLC validation;

chromatography; vitamin

B1; milk powder

\begin{abstract}
Vitamin B1 plays an important role in the co-enzymatic reactions for energy-rich compounds called ATP (Adenosine Tri Phosphate). Therefore, it should be added to various food products, for example, milk powder. One method that can be used to determine vitamin B1 is SNI number 3751: 2009, but the method is intended for wheat flour. If the method is to be used for the analysis from other samples, such as milk powder, optimization, and validation, are needed. This experiment was carried out using HPLC, C18 column, and UV detector with a wavelength of $254 \mathrm{~nm}$. The mobile phase used is methanol: acetic acid: bi-distilled water $=32: 1: 67(\mathrm{v} / \mathrm{v} / \mathrm{v})$, flow rate $=1$ $\mathrm{mL} /$ minute, isocratic, and reverse phased technique. Method validation parameters include tests of system suitability, linearity, the limit of detection, the limit of quantitation, precision (repeatability), and accuracy. The results showed that the system suitability test was obtained relative standard deviations (\% RSD) for retention time and peak area, tailing factor, resolution, separation factor was $0.297 \%, 1.476 \%$, $1.113,6.693$, and 4.406 respectively. The validation test gets a correlation coefficient (R) of 0.9996 , the limit of detection and limit of quantitation were $0.0122 \mathrm{mg} / 100 \mathrm{~mL}$ and $0.0244 \mathrm{mg} / 100 \mathrm{~mL}$, respectively. The precision test obtained Horwitz's ratio of $0.27 \%$. Accuracy test using CRM obtained \% recovery of $93.79-97.77 \%$. All these results meet the requirements of method validation, so it can be concluded that the method of SNI number 3751: 2009 is valid for the determination of vitamin B1 in milk powder and can be used for routine analysis procedure.
\end{abstract}

\section{Introduction}

Milk powder is one product that is produced from processed fresh milk. This milk is in the form of powder with minimal moisture content. According to the BSN (2015) [1], powder milk is a dairy product obtained by reducing a large portion of water through the drying process of fresh milk with or without the addition of vitamins, minerals, and other food additives.

Vitamins are one of the micronutrients, which are usually added to milk powder. Vitamins are complex organic compounds that are needed in large quantities for the metabolic functions of the human body [2]. Vitamins can be grouped into two main groups, i.e., fat-soluble vitamins which include vitamins $A, D, E$, and K and water- soluble vitamins consisting of vitamin $\mathrm{C}$ and vitamin $\mathrm{B}$. Vitamin B1 (or thiamine) is a vitamin that acts as a coenzyme in reaction to carbohydrates to produce energy by forming energy-rich compounds called ATP (Adenosine Triphosphate) in the human body. Vitamin B1 can only be stored in limited quantities in the body, such as in the liver, kidneys, heart, brain, and muscles. Vitamin B1 cannot be made in the human body, so it needs to be supplied from food consumed, such as milk [3].

There is much method for vitamin B1 determination such as method developed by Gámiz-Gracia and Luque de Castro [4], Rada et al. [5], Yantih et al. [6] for pharmaceutical product and Haşimoğlu and Ghodke [7] for veterinary consumption. We choose the SNI method 
because wheat flour and milk powder have the same characteristics. Both of them are powder and food products. According to Eurachem [8], a method should be validated when non-standard methods, laboratorydesigned/developed methods, standard methods used outside their intended scope, and amplifications and modifications of standard methods. SNI method number 3751: 2009 is for wheat flour, so it is needed to be validated when we want to apply to milk powder as wheat flour and milk powder has different matrices.

The purpose of this experiment is to validate the testing method of vitamin B1 content milk powder and ensure that the analytical method is accurate, specific, and reliable so that this method can be used as a routine method for analyzing vitamin B1 in milk powder samples.

\section{Material and Methods}

This experiment consists of three stages, namely the preparation, testing, and processing of data. The preparation stage includes the preparation of reagents, mobile phase solutions, standard series, sample preparation, and conditioning of high-performance liquid chromatography (HPLC). The testing stages include a test of system suitability, linearity test, the limit of detection and limit of quantitation (LOD \& LOQ), precision (repeatability), and accuracy [7]. The data processing stage is done by calculating the results of the validation data and estimating the uncertainty of the test results and then comparing the results of the validation method with terms of acceptance. The method is valid and can be used as a routine analysis method if all method validation parameters meet the acceptability limit $[8,9]$.

\subsection{Equipment and Materials}

The equipment used in this experiment was highperformance liquid chromatography (Waters e2695) equipped with Empower 3 Chromatography software, analytical balance (Mettler Toledo AL 204), water bath (Memmert WNB 14), ultrasonic bath (Elma S100H), magnetic stirrer (Cimarec II), pH meter ( Toledo MP 220), beaker glass ( 50 and 500 ) mL, graduated cylinder ( 50 and 500) $\mathrm{mL}$, volumetric pipette $(0.5 ; 1 ; 2 ; 5 ; 10) \mathrm{mL}$, volumetric flask ( 50 and 100) $\mathrm{mL}$, the vial of $2 \mathrm{~mL}$, syringe (3 and 5) $\mathrm{mL}$ and filter membrane $0.45 \mu \mathrm{m}$.

The materials used in this experiment consisted of chocolate powder milk Certified Reference Material (ERM BD600) thiamin $4.5 \pm 0.6 \mathrm{mg} / \mathrm{kg}$, hydrochloric acid (Merck) $0.1 \mathrm{~N}$, sodium acetate (Merck) $2 \mathrm{M}$, standard vitamin B1 (Merck), glacial acetic acid (Merck), methanol (Merck), double distilled water, and hexane-1-sulfonic acid sodium salt (Merck).

\subsection{Preparation of a standard solution of Vitamin B1}

The standard vitamin B1 was weighed $0.0100 \mathrm{~g}$ into a $50 \mathrm{~mL}$ beaker glass, then added $50.00 \mathrm{~mL}$ of $0.1 \mathrm{~N}$ hydrochloric acids quantitatively. This standard solution is stirred with a magnetic stirrer, then heated in a water bath with a temperature of $95-100^{\circ} \mathrm{C}$ for 30 minutes. This standard solution is cooled at room temperature $\left( \pm 25^{\circ} \mathrm{C}\right)$ then the $\mathrm{pH}$ of the solution is adjusted to $\mathrm{pH} 4.5$ with sodium acetate $2 \mathrm{M}$ solution. This standard solution is put into a $100 \mathrm{~mL}$ volumetric flask and diluted with double distilled water to the mark, then homogenized and filtered with a filter membrane of $0.45 \mu \mathrm{m}$. A standard solution of $10 \mathrm{mg} / 100 \mathrm{~mL}$ of vitamin B1 was taken as much as $5.00 \mathrm{~mL}$ and then put into a $50 \mathrm{~mL}$ volumetric flask to make a standard solution of $1 \mathrm{mg} / 100 \mathrm{~mL}$. The standard solution of $1 \mathrm{mg} / 100 \mathrm{~mL}$ of vitamin B1 was taken $(0.5 ; 1 ; 2$; 6 ; 12) $\mathrm{mL}$ then put into $50 \mathrm{~mL}$ volumetric flask, respectively to make concentration (0.01; $0.02 ; 0.04 ; 0.12$; $0.24) \mathrm{mg} / 100 \mathrm{~mL}$. This standard solution is diluted with double distilled water and then homogenized.

\subsection{Preparation of milk powder samples}

Milk powder weighed $5.5000 \mathrm{~g}$ into a $50 \mathrm{~mL}$ beaker glass and added $0.1 \mathrm{~N}$ hydrochloric acid as much as 50.00 $\mathrm{mL}$ quantitatively. The sample solution is stirred with a magnetic stirrer then heated with a water bath at a temperature $(95-100)^{\circ} \mathrm{C}$ for 30 minutes. The sample solution is cooled at room temperature $\left( \pm 25^{\circ} \mathrm{C}\right)$ then the $\mathrm{pH}$ of the solution is adjusted to reach $\mathrm{pH} 4.5$ with a $2 \mathrm{M}$ sodium acetate solution. The sample solution is put into a $100 \mathrm{~mL}$ volumetric flask and diluted with double distilled water to the mark and then homogenized. The sample solution is filtered with Whatman filter number 42 and then filtered again with a filter membrane $0.45 \mu \mathrm{m}$.

\subsection{Preparation of mobile phase solution}

The mobile phase solution consists of methanol: acetic acid: water (32: 1: $67, \mathrm{v} / \mathrm{v} / \mathrm{v})$ prepared as much as $500 \mathrm{~mL} .5 \mathrm{~mL}$ of acetic acid and $335 \mathrm{~mL}$ of double-distilled water (1:67) were put into a $500 \mathrm{~mL}$ beaker glass and then added $0.4718 \mathrm{~g}$ hexane-1-sulfonic acid sodium salt. The solution is stirred until dissolved then filtered with filter membrane $0.45 \mu \mathrm{m}$. The acetic acid solution and the water are treated for 20 minutes then put into the mobile phase container. Methanol is prepared and put into other mobile phase containers. The mobile phase solution is mixed in the HPLC instrument with a ratio of methanol and a mixture of acetic acid-water $=32: 68(\mathrm{v} / \mathrm{v})$

\subsection{Validation parameters}

Validation of the analytical method deals to ensure that the developed method is acceptable and reliable for its deliberate purpose. As per ICH guidelines, the developed HPLC method was validated for different validation characteristics such as system suitability, selectivity, linearity, precision, accuracy, LOD, and LOQ.

\subsubsection{System suitability}

The system suitability ensures the validity and specificity of the developed method. System suitability test was performed by measuring chromatographic parameters such as peak area, retention time, theoretical plates as well as tailing factor and by determining the 
standard deviation (RSD) for each parameter. The percent RSD of peak area $(<2)$, tailing factor $(<2)$, and theoretical plates $(\mathrm{N}>2000)$ were within the acceptable limits $[10$, 11].

\subsubsection{Specificity}

The specificity of a method is the ability of a method to measure certain substances, carefully and thoroughly, in the presence of other components that might be in the sample matrix. For the selectivity test, the substance to be tested must be determined first. Then made a standard solution, test solution and the blank solution is then tested by the method, whether the method can separate the analyte from the sample matrix

\subsubsection{Linearity}

Linearity is the ability of the analytically-developed procedure to check the result of the sample analytes, whether it is linear to its concentration. The linearity of the method was tested by analyzing different concentrations range of the analytes. The regression analysis data for the calibration curve shows a linear relation over this concentration range for analytes. The correlation coefficient value was found to be $\mathrm{R}>0.995$ [9, 12], which suggested excellent correlation and good linearity for the optimized method.

\subsubsection{Precision (Repeatability)}

The precision was carried out by analyzing samples of 7 replications using HPLC. From the seven replications, the value of \% RSD was calculated and compared with \% RSD (Horwitz), so the Horwitz ratio was obtained. Horwitz ratio can be accepted if the value $<2$.

\subsubsection{Accuracy (\%Recovery)}

The accuracy test is done by analyzing the Certified Reference Material for milk powder four times. \% recovery can be obtained by comparing the CRM measurement results and CRM concentration on the certificate.

$\%$ recovery $=\frac{\text { measurement concentration }}{\text { theoritical concentration }} \times 100 \%$

\subsubsection{Limit of Detection (LOD) and Limit of Quantitation (LOO)}

LOD and LOQ values are obtained from statistical calculations through linear regression from the calibration curve. According to (NATA) [13], LOD and LOQ can be calculated using the formula:

$\mathrm{LOD}=(3 \times \mathrm{Sy} / \mathrm{x}) / \mathrm{b}$

$\mathrm{LOQ}=(10 \times \mathrm{Sy} / \mathrm{x}) / \mathrm{b}$

Notes:

Sy/x: residual standard deviation from a calibration curve b : slope

\subsection{Determination of Vitamin B1 content in powder} milk

HPLC should be conditioned first before used.

Table 1. Parameters of High-Performance Liquid Chromatography conditions

\begin{tabular}{cc}
\hline Instrument & $\begin{array}{c}\text { HPLC Waters e2695 with } \\
\text { Separations Module }\end{array}$ \\
\hline Column & InertSustain C18 $4.6 \times 150 \mathrm{~mm}, 5 \mu \mathrm{m}$ \\
Detector & UV Detector with a wavelength of \\
& $254 \mathrm{~nm}$ \\
Flow rate & $1.0 \mathrm{~mL} /$ minute \\
Time & 15 minutes \\
Technique & Isocratic \\
Injection & $20 \mu \mathrm{L}$ \\
volume & \\
\hline
\end{tabular}

The content of vitamin B1 in powdered milk can be obtained by plotting the peak area of the sample solution into the calibration curve so that the measured concentration is obtained, and then the vitamin B1 content in the test sample can be calculated based on the weight and volume of the solution.

$$
\begin{gathered}
C\left(\frac{m g}{100 m L}\right)=\frac{y-a}{b} \\
\text { The content of vitamin } B 1\left(\frac{m g}{100 g}\right)=C \times \frac{V s}{W}
\end{gathered}
$$

Notes:

$\mathrm{C}$ : measured concentration (mg/100 mL)

Vs: volume of sample solution $(\mathrm{mL})$

W: sample weight $(\mathrm{g})$

\section{Results and Discussion}

\subsection{System suitability test}

Before conducting the analysis, we need to do a system suitability test to ensure that the HPLC is functioning properly. The standard solutions of vitamin B1 were measured to know the retention time of the thiamin. After we know the retention time of the thiamin, the sample was injected eight times to determine the repeatability of the area and retention time. From the chromatogram in Figure 1, we can get the system suitability data as follows:

Table 2. System suitability parameters

\begin{tabular}{cccc}
\hline Parameters & $\begin{array}{c}\text { Data } \\
\text { obtained }\end{array}$ & \%RSD & $\begin{array}{c}\text { Requirement } \\
{[10,11]}\end{array}$ \\
\hline $\begin{array}{c}\text { Peak area } \\
\text { Retention } \\
\text { time }\end{array}$ & $22932+339$ & 1.476 & $\mathrm{RSD}<2$ \\
$\begin{array}{c}\text { Tailing } \\
\text { factor }\end{array}$ & $1.113+0.021$ & & $\mathrm{RSD}<2$ \\
$\begin{array}{c}\text { Resolution } \\
\text { Retention } \\
\text { factor }\end{array}$ & $6.693+0.257$ & $\mathrm{~T} \leq 2$ \\
\hline
\end{tabular}




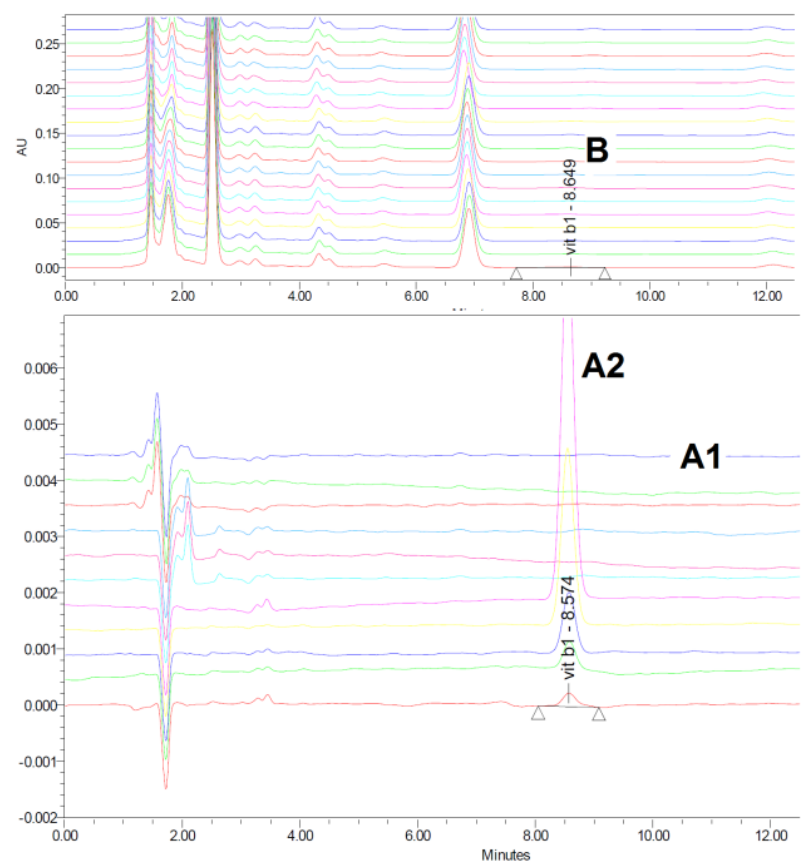

Figure 1. Chromatogram of blank (A1), standard thiamin (A2) and sample thiamin (B), measured using HPLC with the mobile phase methanol: acetic acid-water (32:68), column C18 $4.6 \times 150 \mathrm{~mm} 5 \mu \mathrm{m}$, flow rate $1 \mathrm{ml} / \mathrm{minute}$ and wavelength $254 \mathrm{~nm}$

\subsection{Specificity}

Based on the chromatogram in Figure 1, it can be concluded that a retention time of 8.624 is specific for thiamin. It means that this method has good selectivity because the retention time of analyte is far from the other peak $(R=6.693)$, and the retention time of the analyte is not disturbed by the sample matrix.

\subsection{Linearity}

Linearity tests were carried out by measuring the peak area of a standard series of vitamin B1 at concentrations (0.0100;0.0200;0.0400;0.1200;0.2400) $\mathrm{mg} / 100 \mathrm{~mL}$. The standard series concentrations are made in the range (50-150)\% of the estimated or expected concentration of the analyte in the test sample. Standard series solutions were prepared at five different concentrations with solution preparation three times repetition. The chromatogram and calibration curve for standard vitamin B1 can be seen in Figure 2.

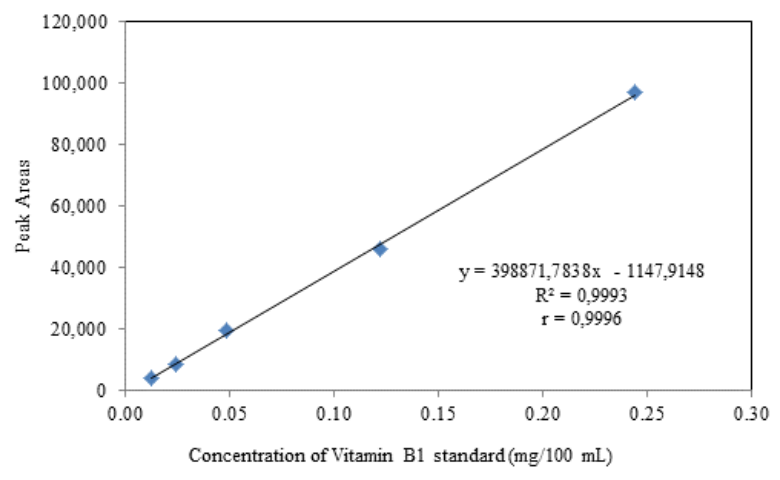

Figure 2. Calibration Curve of Vitamin B1 standard
The curve shows the relationship between concentration and peak area. The line connecting the points on the curve above is called the regression line or correlation line. The parameter that states the relationship between two variables (on the $\mathrm{x}$-axis and $\mathrm{y}$ axis) is called the correlation coefficient. The magnitude of the correlation coefficient ( $r$ ) on the calibration curve above is 0.9996 . This value meets the requirements of $r>$ $0.9950[9,12]$. The slope value on the calibration curve can be used to see sensitivity. The slope value on the curve above is 398871.78 indicating high sensitivity. Intercept is the intersection point at $\mathrm{y}$ when $\mathrm{x}$ is 0 . Ideally, the intercept is 0 , but the intercept on the curve above is negative. When y is 0 , and the intercept is interpolated to the regression equation, an $\mathrm{x}$ value of $0.002878 \mathrm{mg} / 100$ $\mathrm{mL}$ is obtained.

\subsection{Precision (repeatability)}

Precision is useful to see the repeatability of the analytical method carried out under the same conditions of the tool, place, and analyst, in the next test period. Measurements were made with seven replications. The results of the vitamin B1 precision test can be seen in Table 3

Table 3. Results for precision test for determination of Vitamin B1.

\begin{tabular}{|c|c|c|c|c|}
\hline No. & Area & $\begin{array}{l}\text { Weight of } \\
\text { sample (g) }\end{array}$ & $\begin{array}{l}\text { Content of } \\
\text { Vitamin B1 } \\
(\mathrm{mg} / 100 \mathrm{~g})\end{array}$ & $\begin{array}{l}\text { Require- } \\
\text { ment [11] }\end{array}$ \\
\hline 1 & 22959 & 5.5018 & 1.126 & \\
\hline 2 & 22995 & 5.5022 & 1.128 & \\
\hline 3 & 22697 & 5.5022 & 1.114 & \\
\hline 4 & 22788 & 5.5028 & 1.118 & \\
\hline 5 & 23373 & 5.5052 & 1.145 & \\
\hline 6 & 22260 & 5.5015 & 1.093 & \\
\hline 7 & 22375 & 5.5018 & 1.098 & \\
\hline Total & 159447.0 & 38.518 & 7.822 & \\
\hline Average & 22778.1 & 5.5030 & 1.117 & \\
\hline \multicolumn{3}{|c|}{ SD } & 0.02 & \\
\hline \multicolumn{3}{|c|}{$\%$ RSD } & 1.61 & \\
\hline \multicolumn{3}{|c|}{ \% RSD(Horwitz) } & 6 & \\
\hline \multicolumn{3}{|c|}{$\begin{array}{c}\text { Horwirz ratio = } \\
(\% R S D / \% R S D(\text { Horwitz })\end{array}$} & 0.27 & $<2$ \\
\hline
\end{tabular}

Based on precision results, the Horwitz ratio of the sample is 0.27 , it is still less than 2 , so the precision is still within the acceptable limit.

\subsection{Accuracy}

Accuracy testing is performed to determine the closeness between the measured value and the accepted real value, which is expressed as percent recovery. Accuracy testing is carried out using a Certified Reference Material, whose purity is known. CRM is treated according to the test sample preparation method. The accuracy testing results can be seen in Table 4 . 
Tabel 4. Results for accuracy test for determination of Vitamin B1

\begin{tabular}{|c|c|c|c|c|c|c|c|}
\hline No. & 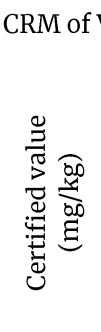 & 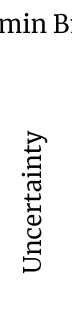 & 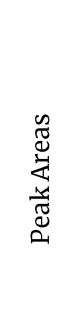 & 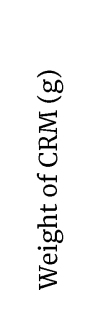 & 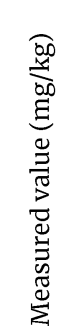 & 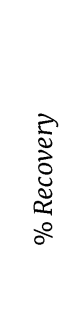 & 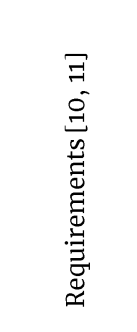 \\
\hline 1 & 4.5 & 0.6 & 6965 & 4.7262 & 4.40 & 97.77 & $92-105 \%$ \\
\hline 2 & 4.5 & 0.6 & 7044 & 4.7079 & 4.46 & 99.07 & \\
\hline 3 & 4.5 & 0.6 & 6779 & 4.7079 & 4.32 & 95.98 & \\
\hline 4 & 4.5 & 0.6 & 6591 & 4.7079 & 4.22 & 93.79 & \\
\hline
\end{tabular}

Based on Table 4, the obtained accuracy is in the range of $93.79-99.07 \%$. The accuracy of this method is good, indicated by recovery values that are close to $100 \%$

\subsection{Limit of detection (LOD) and limit of quantitation (LOO)}

The theoretical LOD and LOQ are obtained from statistical calculations from the calibration curve data. From the theoretical LOD and LOQ, the next step was confirmed by making and analyzing standards with a concentration of theoretical LOD and LOQ. The theoretical LOD and LOQ calculations can be seen in Table 5 .

Table 5. Calculation of theoretical LOD and LOQ

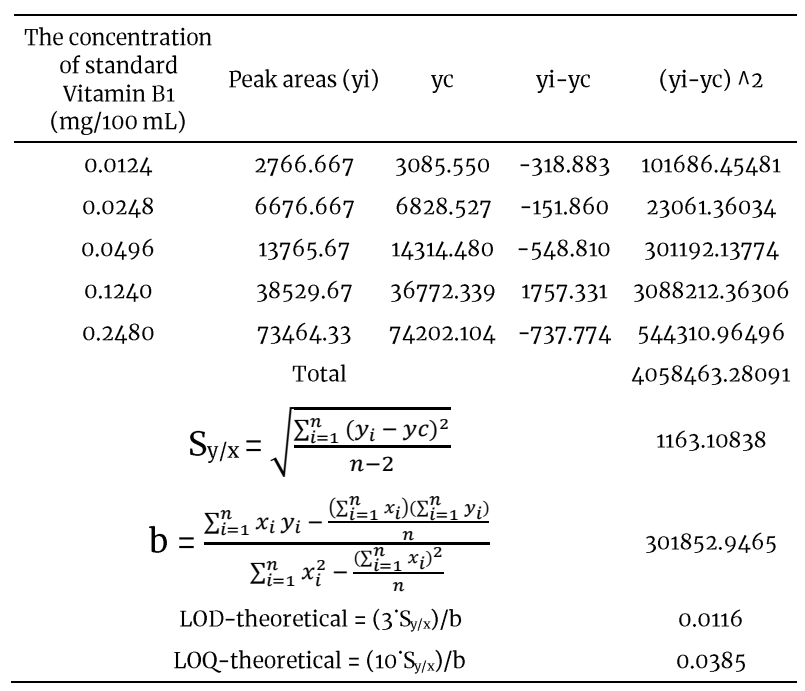

From Table 5, theoretical LOD and theoretical LOQ were obtained for $0.0116 \mathrm{mg} / 100 \mathrm{~mL}$ and $0.0385 \mathrm{mg} / 100$ $\mathrm{mL}$, respectively. From this theoretical LOD, it is necessary to confirm these values by making and analyzing standard solutions at these concentrations, but these concentrations can be raised or lowered until a peak that is well-read (positive response), while the LOQ value must meet the requirements of precision and accuracy.
Tabel 6. Confirmation of theoretical LOD and LOQ

\begin{tabular}{|c|c|c|c|c|c|}
\hline \multirow{2}{*}{ Number } & \multicolumn{2}{|c|}{$\begin{array}{c}\text { Concentration of standard } \\
0.0122 \mathrm{mg} / 100 \mathrm{~mL}\end{array}$} & \multicolumn{2}{|c|}{$\begin{array}{c}\text { Concentration of } \\
\text { standard } 0.0244 \\
\text { mg/100mL }\end{array}$} & \multirow{2}{*}{ 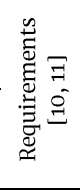 } \\
\hline & $\begin{array}{l}\text { Peak } \\
\text { areas }\end{array}$ & $\begin{array}{c}\begin{array}{c}\text { Measured } \\
\text { concentration } \\
(\mathrm{mg} / 100 \mathrm{~mL})\end{array} \\
\end{array}$ & Peak areas & $\begin{array}{c}\text { Measured } \\
\text { Concentration } \\
(\mathrm{mg} / 100 \mathrm{~mL})\end{array}$ & \\
\hline 1 & 4203.045 & 0.0134 & 8115.923 & 0.0232 & \\
\hline 2 & 4608.393 & 0.0144 & 8255.696 & 0.0236 & \\
\hline 3 & 3281.951 & 0.0111 & 8507.633 & 0.0242 & \\
\hline Average & 4031.1297 & 0.0130 & 8293.0840 & 0.0237 & \\
\hline SD & & 0.001704 & & 0.000498 & \\
\hline$\%$ RSD & & 13.12 & & 2.10 & $\begin{array}{c}< \\
2.68 \%\end{array}$ \\
\hline & Rec & 106.43 & & 97.01 & $\begin{array}{r}92- \\
105 \%\end{array}$ \\
\hline
\end{tabular}

$\%$ Rec $=\frac{\text { means conc. }}{\text { theoretical conc. }} \times 100 \%$

Based on the confirmation results, the LOQ and LOD values are $0.0122 \mathrm{mg} / 100 \mathrm{~mL}$ and $0.0244 \mathrm{mg} / 100 \mathrm{~mL}$.

\subsection{Estimation of uncertainty $[14,15]$}

The first step in determining the uncertainty is the identification and analysis of sources of uncertainty through a Fishbone diagram. The Fishbone diagram of the estimation of the uncertainty of determining vitamin B1 content in powder milk can be seen in Figure 3.

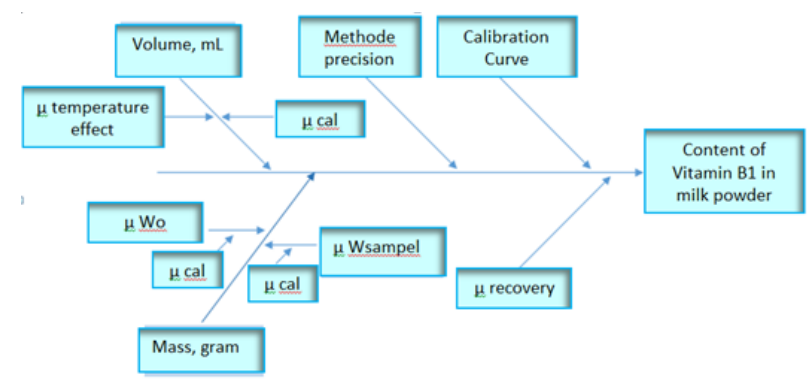

Figure 3. Fishbone diagram of the estimation of uncertainty of determining vitamin B1 content

Notes:

$\mu$ cal: uncertainty of the calibration

$\mu$ Wo: uncertainty of sample pan weight

$\mu$ Wsample: uncertainty of sample weight

$\mu$ recovery: uncertainty of \%recovery

From each of the standard uncertainties, the combined uncertainties can be calculated as follows:

Table 7. Source of standard uncertainty for calculating combined uncertainty

\begin{tabular}{cccccc}
\hline Source of uncertainty & $\mathrm{X}$ & Unit & $\mu(\mathrm{x})$ & $\mu(\mathrm{x}) / \mathrm{X}$ & $(\mu(\mathrm{x}) / \mathrm{X}) \wedge 2$ \\
\hline Calibration curve & 0.0615 & $\mathrm{mg} / 100 \mathrm{~mL}$ & 0.0018 & 0.0287 & 0.000824836 \\
Method Precision & - & $\mathrm{mg} / 100 \mathrm{~g}$ & - & 0.0161 & 0.00025921 \\
Mass of sample & 5.5025 & $\mathrm{~g}$ & 0.00021 & $3.85519 \mathrm{E}-05$ & $1.4863 \mathrm{E}-09$ \\
Volume of sample & 100 & $\mathrm{~mL}$ & 0.0838 & 0.00083815 & $7.02496 \mathrm{E}-07$ \\
Recovery & 96.66 & $\%$ & 6.539 & 0.0676 & 0.004576 \\
\hline
\end{tabular}

So combined uncertainty ( $\mu \mathrm{Cs})$ is:

$\mu \mathrm{Cs}=1.117 \times \sqrt{\left(\frac{0.0018}{0.0615}\right)^{2}+(0.0161)^{2}+\left(\frac{6.539}{96.66}\right)^{2}+\left(\frac{0.0838}{100}\right)^{2}+\left(\frac{0.00021}{5.5025}\right)^{2}}$

$=0.0840 \mathrm{mg} / 100 \mathrm{~g}$ 
For a $95 \%$ confidence level, the coverage factor $\mathrm{k}=2$ is used, so that the expanded uncertainty $(\mathrm{U})$ is obtained for:

$$
\mathrm{U}=2 \times 0.0840=0.1681 \mathrm{mg} / 100 \mathrm{~g}
$$

\section{Conclusion}

The system suitability test was obtained relative standard deviations (\% RSD) for retention time and peak area, tailing factor, resolution, separation factor was $0.297 \%, 1.476 \%, 1.113,6.693$, and 4,406 respectively. The validation test gets the correlation coefficient (r) of 0.9996, the limit of detection and limit of quantitation were $0.0122 \mathrm{mg} / 100 \mathrm{~mL}$ and $0.0244 \mathrm{mg} / 100 \mathrm{~mL}$, respectively. While the precision test obtained the Horwitz ratio of 0.27. Accuracy test using CRM obtained a percent recovery of $93.79-97.77 \%$. All these results meet the requirements of method validation, so it can be concluded that the method of SNI number 3751: 2009 is valid for the determination of vitamin B1 in milk powder and can be used for routine analysis procedure.

\section{Acknowledgment}

The authors wish to thank to Politeknik AKA Bogor, Ministry of Industry of Indonesia for providing the research fund

\section{References}

[1] Badan Standardisasi Nasional, Susu Bubuk, in, Badan Standardisasi Nasional, Jakarta, 2015

[2] William Alexander Newman Dorland and A.A. Mahode, Kamus saku kedokteran Dorland, 31st ed., Elsevier (Singapore), 2012

[3] F.G. Winarno, Kimia Pangan dan gizi, P.T. Gramedia, 1984

[4] L. Gámiz-Gracia and M. D. Luque de Castro, An HPLC Method for the Determination of Vitamin B1, Caffeine, Acetylsalicylic Acid, and The Impurities of Salicylic Acid in a Pharmaceutical Preparation, Journal of Liquid Chromatography \& Related Technologies, 20,13, (1997), 2123-2133

https://doi.org/10.1080/10826079708005570

[5] Amidzic Rada, Brboric Jasmina, Cudina Olivera and Vladimirov Sote, RP-HPLC Determination of vitamins B1, B3, B6, folic acid and B12 in multivitamin tablets, Journal of the Serbian Chemical Society, 70, 10, (2005), 1229-1235

[6] Novi Yantih, Diah Widowati, Wartini and Tiwi Aryani, Validation of HPLC method for determination of thiamine hydrochloride, riboflavin, nicotinamide, and pyridoxine hydrochloride in syrup preparation, Canadian Journal on Scientific and Industrial Research, 2, 7, (2011), 269-278

[7] Ahmet Haşİmoğlu and Shantanu B Ghodke, A novel RP-HPLC method for simultaneous determination of vitamins $\mathrm{B}_{1}, \mathrm{~B}_{2}, \mathrm{~B}_{3}, \mathrm{~B}_{6}$ and $\mathrm{C}$ in oral powder for veterinary consumption, Marmara Pharmaceutical Journal, 22, 4, (2018), 484-492 https://doi.org/10.12991/jrp.2018.89
[8] Eurachem, The Fitness for Purpose of Analytical Methods: A Laboratory Guide to Method Validation and Related Topics, Eurachem, 2014

[9] AOAC, AOAC Guidelines for Single Laboratory; Validation of Chemical Methods for Dietary Supplements and Botanicals, in, 2002,

[10] Yandi Syukri, Ronny Martien, Endang Lukitaningsih and Agung Endro Nugroho, Quantification of Andrographolide Isolated from Andrographis paniculata Nees Obtained from Traditional Market in Yogyakarta Using Validated HPLC, Indonesian Journal of Chemistry, 16, 2, (2016), 190-197 https://doi.org/10.22146/ijc.21163

[11] Bhaskar Kurangi, Sunil Jalalpure and Satveer Jagwani, A validated stability-indicating HPLC method for simultaneous estimation of resveratrol and piperine in cubosome and human plasma, Journal of Chromatography B, 1122-1123, (2019), 39-48 https://doi.org/10.1016/j.jchromb.2019.05.017

[12] Retno Puji Lestari, Resi Gifrianto and Anwar Hadi, Penentuan Limit Deteksi Pengujian Gas Hidrogen Klorida $(\mathrm{HCl})$ dari Emisi Sumber Tidak Bergerak Menggunakan Kromatografi Ion, Ecolab, 11, 1, (2017), 32-41 https://doi.org/10.20886/jklh.2017.11.1.32-41

[13] National Association of Testing Authorities (NATA), Specific Accreditation Criteria: ISO/IEC 17025 Application Document, Manufactured Goods Annex, Physical performance testing - General in, National Association of Testing Authorities (NATA), Australia, 2018

[14] Singapore Accreditation Council, Technical Guide 2: A Guide on Measurement Uncertainty in Chemical \& Microbiological Analysis, in, Singapore Accreditation Council, Singapore, 2019

[15] Eurachem, EURACHEM/CITAC Guide Quantifying Uncertainty in Analytical Measurement, in, 2012 